\title{
Constructing an Instrument with Behavioral Scales to Assess Teaching Quality in Blended Learning Modalities
}

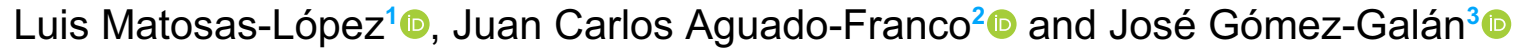 \\ ${ }^{1}$ Department of Financial Economics, Accounting and Modern Language, Universidad Rey Juan Carlos, Spain \\ ${ }^{2}$ Economía de la Empresa (ADO), Economía Aplicada II y Fundamentos Análisis Económico, Universidad Rey Juan Carlos, Spain \\ ${ }^{3}$ CICIDE-Research Center on International Cooperation in Educational Development, Metropolitan University AGMUS, Puerto Rico
}

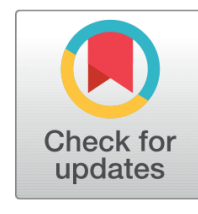

Received 15-02-2019
Revised 28-02-2019
Accepted 06-05-2019
Published 15-07-2019

Corresponding Author

Luis Matosas-López,

luis.matosas@urjc.es

Rey Juan Carlos University, Paseo de Artilleros s/n, 28032, Madrid, Spain

DOI https://doi.org/10.7821/

naer.2019.7.410

Pages: 142-165

Distributed under

Creative Commons CC BY 4.0

Copyright: (C) NAER Journal of New Approaches in Educational Research 2019

\section{OPEN ACCESS}

\section{ABSTRACT}

The assessment of teaching quality in blended learning modalities has become a key element in the context of higher education. However, current evaluation systems present certain limitations. Behavioral scales overcome many of these limitations, offering an alternative for this task.

This study describes the process of constructing an assessment instrument with behavioral scales to evaluate university teachers in blended learning modalities, following the BARS (Behavioral Anchored Rating Scales) methodology. The design process included interviews and surveys involving a total of 477 students, as well as a panel of professors who were experts in this teaching modality.

The behavioral scales in the final instrument highlight the importance of certain particularly significant teaching-related aspects of blended learning models, namely: teacher-student communication; learning resources; course design; and the teacher's technical competencies.

The authors conclude that the final instrument provides clear and unambiguous feedback, enables the teacher to take specific corrective measures, and reinforces the formative purpose of evaluation in these modalities.

\section{Keywords EDUCATIONAL QUALITY, TEACHER EFFECTIVENESS EVALUATION, HIGHER EDUCATION, E-LEARNING, VIRTUAL LEARNING}

\section{INTRODUCTION}

The incorporation of Information and Communication Technologies (ICT) into the sphere of education has represented a turning point in how teaching processes are approached. One of the most significant changes prompted by the application of ICT in education is the appearance of blended learning modalities.

Blended learning modalities, which combine face-to-face learning aspects with others typical of online models, have experienced an enormous growth in recent years, becoming an established trend in the higher education context (Park, Yu, \& Jo, 2016). 
Many studies have focused on the challenges posed by the implementation of this teaching modality (García-Ruiz, Aguaded, \& Bartolomé-Pina, 2017; Porter, Graham, Bodily, \& Sandberg, 2016). Among these challenges, the way to evaluate teaching quality has emerged as a key aspect. The assessment of educational quality in online and blended learning contexts differs from that typically applied to assess face-to-face modalities (Vonderwell, Liang, \& Alderman, 2007). It seems obvious that this training model has its own distinct attributes, but are current quality assessment instruments able to address the singularities of these modalities?

Systems to assess quality in online and blended learning modalities belong to two large groups: (a) systems which use data mining techniques or educational data mining (EDM) to evaluate course quality; and (b) systems where surveys help obtain students' perception of teacher performance, the so-called "student evaluation of teaching" (SET).

\subsection{Quality assessment systems based on EDM}

Several reviews show how EDM-based techniques have provided decision-making support in evaluating the quality of online and blended learning courses (Baker \& Yacef, 2009; Romero \& Ventura, 2010 2013).

Information on student activity, accumulated by the LMS (Learning Management System) utilized in these modalities, includes data such as: interactions in discussion forums (Anaya \& Boticario, 2009); the number of course material downloads (Grob, Bensberg, \& Kaderali, 2004), the number of course pages visited by the student, and the time spent browsing each one of them (Hwang, Tsai, Tsai, \& Tseng, 2008). The storage and quantitative analysis of this massive amount of information form the basis for these quality assessment systems (Ai \& Laffey, 2007).

Romero et al. (2004), for example, used evolutionary algorithms and multi-objective optimization techniques to provide the teacher with the knowledge required to improve course effectiveness. Retalis et al. (2006) applied cluster analysis and association rules to obtain information about the learning process, oriented toward course quality assessment. Vranic et al. (2007) analyzed course activity data by means of data mining algorithms, in order to improve certain aspects of the course's educational quality. Vialardi et al. (2008) also used data mining algorithms to provide the teacher with recommendations aimed at improving course design and structure. Likewise, García et al. (2011) developed a system

Table 1 Examples of quality assessment systems in online and blended learning modalities through EDM

Author

Romero et al. (2004)

Retalis et al. (2006)

Vranic et al. (2007)

Vialardi et al. (2008)

García et al. (2011)

Kazanidis et al. (2016)
Instrument / Technique

Evolutionary algorithms

Cluster analysis \& association rules

Data mining algorithms

Data mining algorithms

Association rules

Regression \& archetypal analysis 
of association rules to show the teacher potential modifications that would help enhance course quality. More recently, Kazanidis et al. (2016) developed a system to evaluate course effectiveness using a twofold data analysis: regression analysis; and archetypal analysis of the activity.

\subsection{Quality assessment systems based on SET}

SET is the most commonly used means to assess quality in online and blended learning courses (Thomas \& Graham, 2017). However, in 2004, Bangert highlighted the inability of the existing systems to address teaching practices in online teaching models. Many authors have developed different systems to measure teaching quality in online and blended learning modalities since then.

Table 2 Examples of SET-based quality assessment systems in online and blended learning modalities

\begin{tabular}{ll} 
Author & Instrument / Technique \\
\hline Bangert (2004) & Likert scale with 35 items \\
Stewart et al. (2004) & Likert scale with 44 items \\
Roberts et al. (2005) & Likert scale with 20 items \\
García-Mestanza (2010) & Likert scale with 44 items \\
Rothman et al. (2011) & Likert scale with 25 items \\
Ralston-Berg et al. (2015) & Likert scale with 43 items \\
\hline
\end{tabular}

Bangert himself has put forward his Student Evaluation of Online Teaching Effectiveness (SEOTE). Using constructivism-inspired methodologies typically associated with online teaching, this system offers an assessment instrument with Likert scales, including 35 items with six levels of agreement. That same year, Hong and Stewart et al. (2004) undertook a thorough literature review and developed an instrument with 44 items, using a Likert scale with five levels of agreement. Roberts et al. (2005) created the Telecourse Evaluation Questionnaire (TEQ) by adapting a questionnaire previously utilized to assess face-to-face course quality. This system parallels the original instrument as a 20 -item questionnaire on a Likert scale of five points, ranging from $1=$ Poor to $5=$ Excellent. In 2010, García-Mestanza took several assessment models and the observations of experts within the sphere of university education as a reference to develop another questionnaire with Likert scales, in this case, with 44 items and seven levels of agreement. Rothman et al. (2011) designed and validated a questionnaire based on the revision of best practices in online learning literature with 25 Likert-type questions, using a five-point scale - ranging from $1=$ Strongly disagree to $5=$ Strongly agree. More recently, Ralston-Berg et al. (2015) developed a questionnaire from the rubrics developed in the Quality Matters Project, which has as its goal to improve education quality in online and blended learning contexts. This instrument contains 43 items and uses four assessment levels, from 0 to 3. 


\subsection{Behavioral scales}

However, despite the multiple proposals for quality evaluation and improvement in these modalities, the aforesaid systems face several limitations. Data mining systems fail to offer students' perspective about teacher performance, since they focus on course quality rather than on assessing teacher performance. Likert-type questionnaires likewise present some of the usual problems - the halo effect, leniency error, and bias - already identified in faceto-face modalities (Matosas-López, Leguey-Galán, \& Leguey-Galán, 2019).

Apart from problems mentioned above, both systems suffer from an additional limitation, namely, their inability to provide the teacher with clear and unambiguous feedback. Lack of clarity from the results is an especially touchy problem in the case of online and blended learning modalities. The impossibility of current systems to generate adequate feedback makes it difficult to accomplish the formative purpose of assessment. This reality hinders the introduction of potential innovations through which course quality might improve.

Behavioral scales, or scales that use behavioral episodes, help reduce ambiguity in the interpretation of results by offering the teacher clear post-assessment feedback. Behavioral scales overcome many of the inconsistencies found in conventional quality assessment systems.

Unlike assessment systems based on data mining, behavioral scales are constructed using episodes of the actual teaching activity as observed by the student. Consequently, the authors feel that data-mining-based assessment systems provide a more accurate view of the teacher's real performance throughout the course.

Additionally, Martin-Raugh, Tannenbaum, Tocci, and Reese (2016) explain how measuring systems which utilize surveys with Likert scales can substantially improve thanks to the use of behavioral episodes. Different studies stress that behavioral scales reduce the halo effect and leniency error, as well as the influence of biasing variables (Kell et al., 2017; Klieger et al., 2018).

Not only do behavioral scales help overcome the limitations of data mining systems when it comes to reflecting a detailed image of the teacher's performance or to reducing the typical Likert-scale problems of halo effect, leniency error, and bias; they also make it possible for the teacher to benefit from clear and unambiguous feedback. This will allow the teacher to easily identify areas for improvement and, consequently, to fulfill the training purpose of assessment.

This study describes the process of constructing an instrument with behavioral scales specifically designed to assess teaching quality in blended learning modalities.

Although analyzing instrument validity and reliability lies beyond the scope of this paper, further analysis of these two points was being performed at the time of writing.

\section{MATERIAL AND METHODS}

The research took as its study object the blended learning degree programs at the Universidad Rey Juan Carlos (URJC), a large-sized public university located in Madrid (Spain). 
These degrees programs were: Business Administration and Management; Advertising and Public Relations; Accounting and Finance; Law; Journalism; Science; Service Administration and Engineering; Early Childhood Education; Primary Education; and Tourism. A total of 477 students from different cohorts of the above programs took part in this study, together with a panel of six professors from the same university. This sort of sampling could be interpreted as a convenience sample (Christensen \& Johnson, 2012).

Our research uses the BARS (Behavioral Anchored Rating Scales) methodology, whose guidelines first designed by Smith and Kendall (1963) have served as a reference. Beyond this, the authors followed the proposal made by Kell et al. (2017) to build a BARS instrument through a process which comprises seven different stages.

\subsection{Description of categories}

The study uses the ten teaching categories that the URJC considers when assessing teachers in its blended learning programs, namely: course introduction; evaluation system description; time management; general availability; organizational consistency; evaluation system implementation; dealing with doubts; explanatory capacity; follow-up easiness; and general satisfaction.

During the first stage, a detailed description for the different teaching categories considered in this research was agreed on through triangulation with expert professors at the URJC ( $n=6)$, each of whom had verified teaching experience in blended learning modalities.

\subsection{Compilation of behavioral episodes}

The second stage involved a group of students $(n=37)$ enrolled in the upper-level courses of the blended learning programs examined in this study. For each teaching category, these students provided examples of effective and ineffective behaviors detected in their teachers. In accordance with Flanagan (1954), behavioral episodes were compiled through both semistructured group interviews and personal interviews. The interviews were held face-to-face at the URJC facilities in Madrid, or online through videoconferencing, depending on the participant's place of residence.

The students who took part in this stage using their experiences with their teachers in the blended learning modality as a reference contributed a total of 387 behavioral episodes.

\subsection{Screening of behavioral episodes}

In the third stage, the panel of experts $(n=6)$ performed a detailed reading of the 387 behavioral episodes collected during the previous stage in order to discard any episode that was: a) duplicated, b) ambiguously formulated, c) unintelligible. After identifying the duplicated episodes and those which were poorly formulated, 84 examples disappeared from the initial set, the final number of behavioral episodes finally amounting to 303 . 


\subsection{Retranslation of behavioral episodes}

A second group of students $(n=39)$ participated in the retranslation task that was carried out during the third stage and had as its aim to reclassify each behavioral episode within the category for which it was originally formulated in stage two. An online questionnaire where the participant found the 303 behavioral episodes on one side and the ten categories on the other served as the means to perform this retranslation.

Following this retranslation, the researchers retained only those episodes which at least $70 \%$ of participants had correctly reclassified in the category for which they were formulated. The minimum retranslation standard of $70 \%$ was set in accordance with Dickinson and Zellinger (1980). The reclassification stage ultimately comes to refine the set of behavioral episodes, ensuring that only the most precise and well-defined ones continue in the scale construction process.

Twenty-one of the 303 episodes considered in this stage did not reach the minimum reclassification standard and were thus eliminated. The number of behavioral episodes remaining at the end of this stage was 282 .

\subsection{Clustering into Core Behavioral Aspects (CBA)}

In the fifth stage, following the clustering proposal made by Matosas-López (2018), the behavioral episodes were grouped together into core behavioral aspects, or CBA. This phase had as its purpose to identify the behavioral episodes within each category that referred to similar behaviors.

The panel of professors $(n=6)$ performed a detailed examination of the 282 behavioral episodes resulting from the previous phase. After meticulously reviewing each one of them, the panel determined that the behavioral episodes within each category could be clustered into four subgroups of clearly differentiated CBA (See Appendix A).

Flanagan (1954) guidelines to define critical incidents allowed the experts to state the CBA which produced concise affirmations with strong descriptive power. The CBA were formulated in a positive sense to reflect the behavioral scenario that the teacher should exhibit to meet students' expectations. The CBA wording included the original vocabulary that students used when they first identified the behavioral episodes.

Behavioral episodes were eliminated if they were not analogous to other episodes and they could not be formed into a subgroup or integrated into any existing one. Twenty-six episodes disappeared during this process, thus leaving 256 behavioral episodes which in turn were grouped together into forty CBA subgroups (four per category).

\subsection{Dual evaluation of behavioral episodes}

A total of 401 students selected through simple random sampling took part in this sixth stage aimed at ordering the CBA from the student's perspective, considering the importance that each CBA has for them. The participants completed a dual assessment process that involved the following two tasks: a) evaluation of the CBA in each category; and b) evaluation of the category-representative statement. Both tasks were carried out using an online questionnaire. Students were urged to take the performance of one of their teachers 
during the immediately preceding academic term as a reference for this dual assessment. Seeking to ensure that students completed the evaluation taking different teacher profiles as a reference - and not only those that they most liked or disliked - the choice of teachers was bounded by the researchers.

\subsubsection{Evaluation of CBA in each category}

In this first task, the participants evaluated the four CBA included in each category through a dichotomous rating method using the terms "Fulfilled" or "Not fulfilled".

$\begin{array}{ll}\text { CBA1 } & \text { Teacher defines days and times for online office hours to meet with } \\ \text { students via videoconferencing } \\ \text { CBA2 }\end{array}$

Figure 1 CBA evaluation in the "general availability" category

The dichotomous rating ("Fulfilled" or "Not fulfilled") of the four CBA within each category led to different CBA combinations by category. Each of these combinations represents a different behavioral scenario. For example, the situation represented in Figure 1 is a scenario where the teacher fulfills CBA1 and CBA4 but fails to meet the students' expectations presented in CBA2 and CBA3.

Since each quadruplet of CBA is treated independently, category by category, the dichotomous rating ("Fulfilled" or "Not fulfilled") of CBA creates a maximum of 16 potential scenarios or combinations per category. Considering all ten categories, that process could result in a maximum of 160 potential scenarios or CBA combinations.

\subsubsection{Evaluation of the category-representative statement}

The second task undertaken during this dual assessment system consisted in rating a descriptive statement of the teacher behavior that characterizes this category (one statement per category). This task is completed using a Likert-scale with five levels, which permits to establish an order in CBA combinations.

After participants completed the first task, and on the basis of the previously selected teacher's performance, they rated the statement in each category on a 1-to-5 range.

The first task in this dual assessment system generates different CBA combinations, where some CBA are fulfilled, and others are not. The second task reflects the score that would be associated with each CBA combination — from the student's perspective - on a 
hypothetical Likert scale with five levels. This dual assessment system makes it possible for the researcher to determine the CBA combination that the student would associate with each level of effectiveness.

Upon completion of this dual assessment, the researchers calculated the mean and standard deviation (SD) for each one of the CBA combinations existing in each category. The mean value indicates the point of the scale which the CBA combination in question could occupy in the final instrument. As for SD, it represents the level of agreement between participants when placing that particular combination at the point reflected by the mean.

After checking the mean and SD of each CBA combination, the researchers only retained those combinations where greater consensus existed among participants, using a "minimum SD" criterion. CBA combinations with SD values above 1.5 were thus eliminated. The criterion was set at 1.5, in line with the approach of authors such as Schwab, Heneman, and DeCotiis (1975) or Smith and Kendall (1963).

\subsection{Design and creation of the final scale}

During the last stage, the researchers used the remaining CBA combinations as anchoring points for final scale design.

Instead of adopting a single, identical interval size to generate classes that were exactly the same in all ten categories, the researchers decided to use different, personalized interval sizes for each category which were set as a function of the mean value distribution of the CBA combinations belonging to each category. The researchers calculated this class interval by subtracting the lowest CBA distribution mean value from the highest one, subsequently dividing this difference by the lowest mean value.

Class interval size $=($ Highest CBA mean - Lowest CBA mean $) /($ Lowest CBA mean $)$

Class interval size serves to generate four cutoff points. The first cutoff is obtained by adding class interval size to the lowest distribution mean. As for the second, third and fourth cutoff points, they result from successively adding the interval size value to the previous point. All four cutoff points prove helpful to create the five class intervals in each category. Albeit identical in size within their own category, these intervals are different across categories. Table 3 shows class interval sizes, along with the intervals themselves.

The use of personalized intervals provides the researcher with appropriate classes for the distribution of values in each category. The researcher thus has an optimal number of CBA combinations within each class interval before addressing the final selection.

Lastly, the appropriate CBA combination is selected within each interval, once again paying attention to its $\mathrm{SD}$. The researchers performed the final selection taking the CBA combinations with the lowest $\mathrm{SD}$, i.e. those showing the highest level of agreement among students. The CBA combination was eliminated from the selection in those cases where only a few subjects showed agreement.

Figure 2, which exemplifies one of the final resulting scales, presents the scale that will serve to assess teaching effectiveness in the "general availability" category.

The first anchoring point in this scale corresponds to a situation where none of the four CBA is fulfilled; the second anchoring point reflects joint fulfillment of ACB3 and ACB4; the 
third point represents fulfillment of $\mathrm{ACB} 1$ and $\mathrm{ACB} 4$ also in joint manner; and the fourth anchoring point reflects attainment of ACB1, ACB3 and ACB4. Finally, the highest point is reached when the teacher meets the student's expectations in the four CBA of this category (See Figure 1 to identify CBA).

Table 3 Personalized class intervals by category

\begin{tabular}{|c|c|c|c|c|c|c|}
\hline Category & $\begin{array}{l}\text { Size of class } \\
\text { interval }\end{array}$ & $\begin{array}{l}\text { 1st class } \\
\text { interval }\end{array}$ & $\begin{array}{l}\text { 2nd class } \\
\text { interval }\end{array}$ & $\begin{array}{l}\text { 3rd class } \\
\text { interval }\end{array}$ & $\begin{array}{l}\text { 4th class } \\
\text { interval }\end{array}$ & $\begin{array}{l}\text { 5th class } \\
\text { interval }\end{array}$ \\
\hline Course introduction & 0.72 & $1-2.03$ & $2.04-2.75$ & $2.76-3.47$ & $3.48-4.19$ & $4.20-5$ \\
\hline Evaluation system description & 0.78 & $1-1.78$ & $1.79-2.56$ & $2.57-3.33$ & $3.34-4.11$ & $4.12-5$ \\
\hline Time management & 0.72 & $1-1.97$ & $1.98-2.69$ & $2.70-3.42$ & $3.43-4.14$ & $4.15-5$ \\
\hline General availability & 0.63 & $1-2.28$ & $2.29-2.92$ & $2.93-3.55$ & $3.56-4.18$ & $4.19-5$ \\
\hline Organizational consistency & 0.74 & $1-1.82$ & $1.83-2.56$ & $2.57-3.29$ & $3.30-4.03$ & $4.04-5$ \\
\hline $\begin{array}{l}\text { Evaluation system } \\
\text { implementation }\end{array}$ & 0.74 & $1-1.90$ & $1.91-2.64$ & $2.65-3.38$ & $3.39-4.13$ & $4.14-5$ \\
\hline Dealing with doubts & 0.69 & $1-2.02$ & $2.03-2.70$ & $2.71-3.39$ & $3.40-4.07$ & $4.08-5$ \\
\hline Explicative capacity & 0.69 & $1-2.06$ & $2.07-2.75$ & $2.76-3.44$ & $3.45-4.12$ & $4.13-5$ \\
\hline Follow-up easiness & 0.76 & $1-1.79$ & $1.80-2.54$ & $2.55-3.30$ & $3.31-4.05$ & $4.06-5$ \\
\hline General satisfaction & 0.63 & $1-2.20$ & $2.21-2.84$ & $2.85-3.47$ & $3.48-4.10$ & $4.11-5$ \\
\hline
\end{tabular}

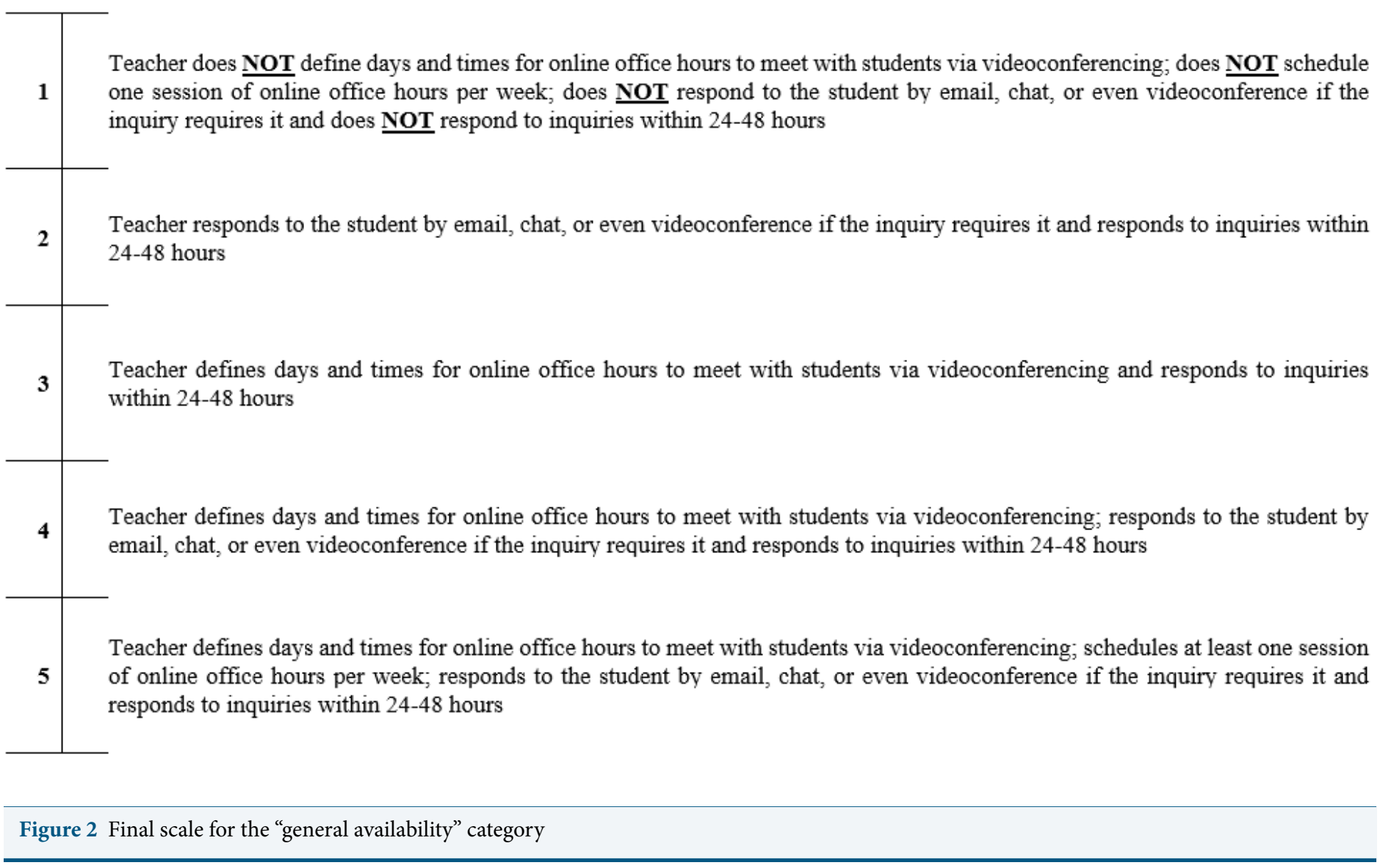


The final instrument, which contains the ten scales generated through the foregoing methodology, is reproduced in its entirety in Appendix B.

\section{RESULTS}

The instrument created here makes it possible to assess teachers in blended learning modalities with regard to ten teaching categories. Each category is represented by a behavioral scale, each of which has five anchoring points established according to CBA combinations. These CBA combinations were generated through the dichotomous rating carried out during the construction process. Out of a maximum of $160 \mathrm{CBA}$ combinations which could have been obtained, this rating process supplied a total of 146 combinations. The number of cases per category varied from thirteen to sixteen CBA combinations (see Table 4).

The highest number of CBA combinations (sixteen) is only reached in the "follow-up easiness" category. By contrast, the "general availability" category shows the lowest number of combinations generated by participants with thirteen CBA combinations.

Out of 146 CBA combinations initially observed, 128 met the lowest SD criterion. Table 4 shows us that between one and four CBA combinations were eliminated from each category according to this criterion. The categories which contain CBA combinations with greater dispersion are "evaluation system implementation" and "general satisfaction", four combinations having been removed within the latter category.

An examination of the behavioral scales that comprise the final instrument for each category reveals several points of interest.

First, it becomes evident in nine of the ten categories that the first anchoring point - the scenario which indicates the lowest level of effectiveness - is represented by the combination of nonfulfillment of all four CBA. The "general satisfaction" category constitutes an

\begin{tabular}{|c|c|c|c|c|}
\hline Category & $\begin{array}{l}\text { No of CBA combinations } \\
\text { generated on stage } 6\end{array}$ & $\begin{array}{l}N^{o} \text { of } C B A \text { combinations } \\
\text { that meet the SD criterion } \\
(S D=1.5) \text { on stage } 7\end{array}$ & $\begin{array}{l}\text { Ranges of SD in the CBA } \\
\text { combinations in the final } \\
\text { instrument }\end{array}$ & $\begin{array}{l}\text { Ranges of means in the } \\
\text { CBA combinations in the } \\
\text { final instrument }\end{array}$ \\
\hline Course introduction & 15 & 14 & $0.44-1.15$ & $1.30-4.66$ \\
\hline $\begin{array}{l}\text { Evaluation system descrip- } \\
\text { tion }\end{array}$ & 15 & 14 & $0.30-1.03$ & $1.24-4.50$ \\
\hline Time management & 14 & 13 & $0.26-0.87$ & $1.25-4.50$ \\
\hline General availability & 13 & 12 & $0.41-1.16$ & $1.65-4.50$ \\
\hline $\begin{array}{l}\text { Organizational consis- } \\
\text { tency }\end{array}$ & 15 & 12 & $0.28-0.88$ & $1.00-4.10$ \\
\hline $\begin{array}{l}\text { Evaluation system imple- } \\
\text { mentation }\end{array}$ & 14 & 11 & $0.34-1.22$ & $1.15-4.50$ \\
\hline Dealing with doubts & 15 & 14 & $0.42-0.99$ & $1.33-4.23$ \\
\hline Explicative capacity & 14 & 12 & $0.38-1.41$ & $1.37-4.38$ \\
\hline Follow-up easiness & 16 & 15 & $0.17-0.99$ & $1.03-4.22$ \\
\hline General satisfaction & 15 & 11 & $0.15-1.15$ & $1.57-4.27$ \\
\hline TOTAL & 146 & 128 & - & - \\
\hline
\end{tabular}


exception to this, because the minimal level of effectiveness does not correlate with a scenario characterized by nonfulfillment of all four CBA, but with one where only one of the CBA is fulfilled. Thus, the minimal level of effectiveness for this category is constituted by the following CBA: Teacher demonstrates knowledge and appropriate skills to use LMS resources, applying them to make the course more attractive (See Appendix B).

The minimal level of performance for the nine categories where the first anchoring point is represented by a situation of nonfulfillment of all four CBA is captured at the second point of the scale. We may therefore state that the CBA or CBA combination assigned to the first anchoring points of the scale reflect the basic level of performance that the student expects for this category (See Appendix B).

As for the middle part of the scale, i.e. anchoring points three and four, these are always represented by two or three CBA fulfillments, depending on the category.

The fifth anchoring point, which indicates the maximum level of teaching effectiveness, concurs in all cases with a CBA combination of fulfillment of the four CBA included in the category.

Finally, in eight categories: the lowest point of the scale reflects a situation of complete nonfulfillment; the second anchoring point shows fulfillment of one CBA; the third anchoring point represents fulfillment of two CBA; anchoring point four concurs with fulfillment of three CBA; and the highest point on the scale is attained when the teacher manages to meet student expectations in all four CBA belonging to the category.

\section{DISCUSSION}

Two types emerge when considering the quality assessment systems used in blended learning modalities, on the one hand, measuring systems based on data mining techniques and, on the other hand, systems with Likert questionnaires. Nonetheless, both types face a variety of limitations, though.

Using an instrument with behavioral scales can help overcome many of the limitations which affect such systems. Behavioral scales allow students to depict their view of the teacher's effort, simultaneously reducing the halo effect, leniency error, and even the influence of biasing variables. The utilization of behavioral scales additionally enables the teacher to obtain clear and unambiguous feedback.

The characteristics of behavioral scales that lead to such improvements include: encouraging individuals who are familiar with the activity under analysis - and who resemble those who will use the resulting instrument - to take part in the construction process; using behavioral examples which can be easily understood by all the parties involved in the assessment; and implementing the same vocabulary and terminology utilized by the student when constructing the final scale Matosas-López and Leguey-Galán (2019); Matosas-López et al. (2019).

These aspects make it easier for both students and teachers to find the meaningful scales when doing evaluation. Students understand the behavioral episodes expressed in the questionnaire, and the teacher obtains useful feedback as well. 
The BARS instrument developed here presents a detailed inventory of behavioral episodes which help assess teaching quality in blended learning modalities unambiguously. Following along the lines of previous studies, the behavioral episodes recorded in the final instrument corroborate the outstanding importance of certain aspects inherent to blended learning models, namely: teacher-student communication; learning resources; course design; and the teacher's technical competencies.

\subsection{Teacher-student communication}

In line with prior research, our findings underscore the important role played by communication within these modalities (Matosas-López, 2018). The scales which appear in the final instrument have to do with aspects relating to communication in three categories: general availability; dealing with doubts; and follow-up easiness.

The "general availability" category shows us the teacher's willingness to address students through different channels (email, chat, and even by videoconference), as well as his/her responsiveness in getting back to students within 24 hours. The category "dealing with doubts" refers to the atmosphere created by the teacher in the course forum, as well as to the use of videoconferencing to address complex questions. As in Rovai, Ponton, Derrick, and Davis (2006), the scale reflects the importance of communication message clarity with regard to this same category. The "follow-up easiness" category stresses the relevance not only of regular reminders but also of the teacher's involvement in motivating the student to participate in the course forum. Both aspects not only help the student keep up with the subject, but they also contribute to creating a bond, thus reducing the impersonal nature of interactions in these virtual contexts.

\subsection{Learning resources}

Sharing the approach of other authors (Sebastianelli, Swift, \& Tamimi, 2015), our final instrument reflects the importance of learning materials when it comes to the assessment of distance teaching in four categories. It is in the "explanatory capacity" category that learning resources play the biggest role. Multimedia elements, such as video lectures, interactive presentations (Sway, Prezi, etc.) and podcasts form part of this category.

The instrument also contains allusions to teaching materials in the "time management", "organizational consistency" and "follow-up easiness" categories. All of these include references to the use of video lectures and to how they can prove helpful. Different studies emphasize the relevance of video lectures not only as the resource most often used by students in these modalities, but also as the key learning quality determinant in virtual environments (Soffer, Kahan, \& Livne, 2017). Within blended learning modalities, video lectures take on the role of conventional classes in face-to-face modalities, thus becoming one of the main learning resources. Furthermore, they stand out for being the one tool which best blends synchronous and asynchronous instruction methodologies. They are: (a) synchronous when the video lecture takes places live with the teacher and the student sharing the broadcast time; and (b) asynchronous when the video lecture is recorded and stored for later viewing. 


\subsection{Course design}

Along the lines of previous research works, the results highlight the extent to which course design helps achieve satisfactory learning experiences (Jaggars \& Xu, 2016). This fact is reflected in four categories: course introduction; organizational consistency; evaluation system description; and general satisfaction.

The "course introduction" and "organizational consistency" categories emphasize the need to define and follow through with programming that is organized into blocks or modules. In tune with Soffer et al. (2017), our instrument shows the importance of organizing the course within the LMS into consistent, well-structured modules that help students manage their time in an orderly manner. This organization makes it possible to mark out intuitive navigation flows thanks to which the student can follow the course through its different sections, thus providing learners with guidelines to structure their work within the platform.

The relevance of design likewise becomes clear in the scale of the "general satisfaction" category, where the second anchoring point mentions the use of an appropriate design and structure within the LMS.

\subsection{The teacher's technical competencies}

In keeping with other authors who emphasize the importance of technical competencies when assessing teaching quality in virtual environments (García-Peñalvo \& Seoane-Pardo, 2015), the instrument constructed here includes considerations about the use of technological resources in every category.

The utilization of the LMS and its functionalities deserves special attention. Like those of Pulham and Graham (2018), our findings stress the importance of the LMS within these modalities. Seven out of ten categories studied here mention the LMS being used by the teacher in different course contexts: from publishing the course introduction video and the teacher's CV (course introduction category) to using the platform's quizzes functionality (evaluation system description category) or the email, chat and forum tools (dealing with doubts category). The results show how providing a learning environment rich in technological resources turns out to be a determining factor when assessing teaching quality in blended learning modalities.

Of interest to the authors is the resulting construction of the scale for the "general satisfaction" category. In its first anchoring point, which represents the basic level of effectiveness, it refers to the teacher's use of LMS technical resources to make the course more appealin.

\section{CONCLUSIONS}

Unlike the quality assessment systems used to date, the BARS instrument developed here removes ambiguity in interpreting the results and offers feedback that enables the teacher to easily identify areas for improvement. 
Likewise, following along the same lines as Matosas-López et al. (2019) in their work dedicated to the student's perception about BARS as a means to assess teaching quality in face-to-face modalities, we believe that the use of these scales in blended learning modalities will most probably be welcomed by students.

In tune with the literature review carried out by Gikandi, Morrow, and Davis (2011) on teacher assessment in online modalities, the feedback provided by the present BARS instrument: a) helps the teacher clearly understand what the expected quality standards are; b) facilitates and incentivizes reflection; c) addresses the gap between the teacher's current performance and what is desired; and d) provides valuable information that can largely help shape the teacher's work in future courses.

Added to this, in our opinion, the utilization of behavioral episodes expressed using students' vocabulary increases their attention and commitment during the evaluation, which can have the additional positive effect of reducing the degree of careless responding in the survey - an issue of great concern in the SET field over the years (Meade \& Craig, 2012) which becomes particularly relevant in the case of distance learning.

The authors conclude that the use of behavioral scales constitutes a suitable alternative to assess university professors in blended learning modalities. Utilizing behavioral episodes helps overcome the typical problem of ambiguity when interpreting results, as seen with conventional measuring systems. Furthermore, the final instrument enables the teacher to take specific corrective measures and encourages the formative purpose of evaluation in these modalities.

\section{REFERENCES}

Ai, J., \& Laffey, J. (2007). Web Mining as a Tool for Understanding Online Learning. MERLOT Journal of Online Learning and Teaching, 3(2). Retrieved from http://jolt.merlot.org/vol3no2/ ai.pdf

Anaya, A., \& Boticario, J. (2009). A data mining approach to reveal representative collaboration indicators in open collaboration frameworks. International Conference on Educational Data Mining (pp. 210-218). Cordoba. Retrieved from http://citeseerx.ist.psu.edu/viewdoc/ download?doi=10.1.1.208.8680\&rep=rep1\&type $=$ pdf

Baker, R., \& Yacef, K. (2009). The state of Educational Data Mining in 2009: A review and future visions. JEDM | Journal of Educational Data Mining, 1(1), 3-17. Retrieved from http://jedm .educationaldatamining.org/index.php/JEDM/article/view/8

Bangert, A. W. (2004). The Seven Principles of Good Practice: A framework for evaluating on-line teaching. Internet and Higher Education, 7(3), 217-232. https://doi.org/10.1016/j.iheduc.2004 .06 .003

Christensen, B., \& Johnson, L. (2012). Educational research: quantitative, qualitative, and mixed approaches. Thousand Oaks: SAGE Publications.

Dickinson, T. L., \& Zellinger, P. M. (1980). A comparison of the behaviorally anchored rating and mixed standard scale formats. Journal of Applied Psychology, 65(2), 147-154. https://doi.org/ 10.1037//0021-9010.65.2.147

Flanagan, J. C. (1954). The critical incident technique. Psychological Bulletin, 51(4), 327-358. https://doi.org/10.1037/h0061470

García, E., Romero, C., Ventura, S., \& Castro, C. D. (2011). A collaborative educational association 
rule mining tool. Internet and Higher Education, 14(2), 77-88. https://doi.org/10.1016/j iheduc.2010.07.006

García-Mestanza, J. (2010). Propuesta de evaluación de la actividad docente universitaria en entornos virtuales de aprendizaje. Revista Española de Pedagogía, 246, 261-280.

García-Peñalvo, F. J., \& Seoane-Pardo, A. M. (2015). Una revisión actualizada del concepto de eLearning: Décimo aniversario. Teoría de La Educación, 16(1), 119-144. https://doi.org/ 10.14201/eks2015161119144

García-Ruiz, R., Aguaded, I., \& Bartolomé-Pina, A. (2017). La revolución del blended learning en la educación a distancia. RIED. Revista Iberoamericana de Educación a Distancia, 21(1). https://doi.org/10.5944/ried.21.1.19803

Gikandi, J. W., Morrow, D., \& Davis, N. E. (2011). Online formative assessment in higher education: A review of the literature. Computers \& Education, 57(4), 2333-2351. https://doi.org/10.1016/ j.compedu.2011.06.004

Grob, H. L., Bensberg, F., \& Kaderali, F. (2004). Controlling open source intermediaries - a Web log mining approach. 26th International Conference on Information Technology Interfaces (pp. 233-242). Zagreb, Croatia. Retrieved from https://www.semanticscholar.org/paper/Controlling-open-source-intermediaries-a-Web -log-Grob-Bensberg/2a8cbc24df53d8ee561168e06ac7531d591e2380

Hwang, G. J., Tsai, P. S., Tsai, C. C., \& Tseng, J. C. R. (2008). A novel approach for assisting teachers in analyzing student web-searching behaviors. Computers \& Education, 51(2), 926-938. https:// doi.org/10.1016/j.compedu.2007.09.011

Jaggars, S. S., \& Xu, D. (2016). How do online course design features influence student performance? Computers \& Education, 95, 270-284. https://doi.org/10.1016/j.compedu.2016.01.014

Kazanidis, I., Theodosiou, T., Petasakis, I., \& Valsamidis, S. (2016). Online courses assessment through measuring and archetyping of usage data. Interactive Learning Environments, 24(3), 472-486. https://doi.org/10.1080/10494820.2014.881390

Kell, H. J., Martin-Raugh, M. P., Carney, L. M., Inglese, P. A., Chen, L., \& Feng, G. (2017). Exploring Methods for Developing Behaviorally Anchored Rating Scales for Evaluating Structured Interview Performance. https://onlinelibrary.wiley.com/doi/full/10.1002/ets2.12152

Klieger, D. M., Kell, H. J., Rikoon, S., Burkander, K. N., Bochenek, J. L., \& Shore, J. R. (2018). Development of the Behaviorally Anchored Rating Scales for the Skills Demonstration and Progression Guide. Retrieved from https://onlinelibrary.wiley.com/doi/full/10.1002/ets2.12210

Martin-Raugh, M., Tannenbaum, R. J., Tocci, C. M., \& Reese, C. (2016). Behaviourally Anchored Rating Scales: An application for evaluating teaching practice. Teaching and Teacher Education, 59, 414-419. https://doi.org/10.1016/j.tate.2016.07.026

Matosas-López, L. (2018). Aspectos de comportamiento básico del profesor universitario en los procesos de valoración docente para modalidades blended learning. Revista Espacios, 39(10), 10-24. Retrieved from http://www.revistaespacios.com/a18v39n17/18391713.html

Matosas-López, L., \& Leguey-Galán, S. (2019). Percepción del alumnado sobre el uso de instrumentos BARS (Behavioral Anchored Rating Scales) para la valoración del profesorado universitario. In AIDIPE (Ed.), XIX Congreso Internacional de Investigación Educativa: Investigación Comprometida para la Transformación Social (pp. 489-594). Madrid: Asociación Interuniversitaria de Investigación Pedagógica.

Matosas-López, L., Leguey-Galán, S., \& Leguey-Galán, S. (2019). Evaluación de la calidad y la eficiencia docente en el contexto de la educación superior: Alternativas de mejora. In D. y L.-M. Gómez-Galán, J. Martín-Padilla, \& C. A. H. (Eds.), La Educación Superior en el Siglo XXI: Una Mirada Multidisciplinaria. Wheaton: Editorial UMET.

Meade, A. W., \& Craig, S. B. (2012). Identifying careless responses in survey data. Psychological 
Methods, 17(3), 437-455. https://doi.org/10.1037/a0028085

Park, Y., Yu, J. H., \& Jo, I. H. (2016). Clustering blended learning courses by online behavior data case study in a Korean higher education institute. Internet and Higher Education, 29, 1-11. https://doi.org/10.1016/j.iheduc.2015.11.001

Porter, W. W., Graham, C. R., Bodily, R. G., \& Sandberg, D. S. (2016). A qualitative analysis of institutional drivers and barriers to blended learning adoption in higher education. Internet and Higher Education, 28, 17-27. https://doi.org/10.1016/j.iheduc.2015.08.003

Pulham, E., \& Graham, C. R. (2018). Comparing K-12 online and blended teaching competencies: a literature review. Distance Education, 39(3), 411-432. https://doi.org/10.1080/01587919.2018 .1476840

Ralston-Berg, P., Buckenmeyer, J., Barczyk, C., Hixon, E., State, P., \& Campus, W. (2015). Students' Perceptions of Online Course Quality: How Do They Measure Up to the Research? Internet Learning Journal, 4(1). https://doi.org/10.18278/il.4.1.2

Retalis, S., Papasalouros, A., Psaromiligkos, Y., Siscos, S., \& Kargidis, T. (2006). Towards Networked Learning Analytics-A concept and a tool. 5th International. Conference Networked. Learning (pp. 1-8). Retrieved from https://pdfs.semanticscholar.org/326d/ 7603df43cdfe1c0feeea10d0115b2a9c09b5.pdf

Roberts, T. G., Irani, T. A., Telg, R. W., \& Lundy, L. K. (2005). The Development of an Instrument to Evaluate Distance Education Courses Using Student Attitudes. American Journal of Distance Education, 19(1), 51-64. https://doi.org/10.1207/s15389286ajde1901_5

Romero, C., \& Ventura, S. (2010). Educational Data Mining: A Review of the State of the Art. IEEE Transactions on Systems, Man, and Cybernetics Part C: Applications \& Reviews, 40(6). https://doi.org/10.1109/TSMCC.2010.2053532

Romero, C., \& Ventura, S. (2013). Data mining in education. Wiley Interdisciplinary Reviews: Data Mining and Knowledge Discovery, 3(1), 12-27. https://doi.org/10.1002/widm.1075

Romero, C., Ventura, S., \& Bra, P. D. (2004). Knowledge discovery with engetic programming for providing feedback to courseware authors. User Modeling and User-Adapted Interaction, 14(5), 425-464. https://doi.org/10.1007/s11257-004-7961-2

Rothman, T., Romeo, L., Brennan, M., \& Mitchell, D. (2011). Criteria for Assessing Student Satisfaction with Online Courses. Journal for E-Learning Security (IJeLS), 1(1). Retrieved from society.org/wp-content/uploads/ijels/published-papers/volume-1 -2011/Criteria-for-Assessing-Student-Satisfaction-with-Online-Courses.pdf

Rovai, A. P., Ponton, M. K., Derrick, M. G., \& Davis, J. M. (2006). Student evaluation of teaching in the virtual and traditional classrooms: A comparative analysis. Internet and Higher Education, 9(1), 23-25. https://doi.org/10.1016/j.iheduc.2005.11.002

Schwab, D. P., Heneman, I. I. I., \& DeCotiis, T. A. (1975). Behaviorally anchored rating scales: A review of the literature. Personnel Psychology, 28(4), 549-562. https://doi.org/10.1111/ j.1744-6570.1975.tb01392.x

Sebastianelli, R., Swift, C., \& Tamimi, N. (2015). Factors Affecting Perceived Learning, Satisfaction, and Quality in the Online MBA: A Structural Equation Modeling Approach. Journal of Education for Business, 90(6), 296-305. ttps://doi.org/10.1080/08832323.2015.1038979

Smith, P. C., \& Kendall, L. M. (1963). Retranslation of Expectations : an approach to the construction of unambiguous anchors for rating scales. Journal of Applied Psychology, 47(2), 149-155. https://doi.org/10.1037/h0047060

Soffer, T., Kahan, T., \& Livne, E. (2017). E-assessment of online academic courses via students' activities and perceptions. Studies in Educational Evaluation, 54, 83-93.

Stewart, I., Hong, E., \& Strudler, N. (2004). Development and Validation of an Instrument for Student Evaluation of the Quality of Web-Based Instruction. American Journal of Distance 
Education, 18(3), 131-150. https://doi.org/10.1207/s15389286ajde1803_2

Thomas, J. E., \& Graham, C. R. (2017). Common Practices for Evaluating Post-Secondary Online Instructors. Online Journal of Distance Learning Administration, 20(4). Retrieved from https:// eric.ed.gov/?id=EJ1165470

Vialardi, C., Bravo, J., \& Ortigosa, A. (2008). Improving AEH courses through log analysis. Journal of Universal Computer Science, 14(17). Retrieved from http://tangow.ii.uam.es/opah

Vonderwell, S., Liang, X., \& Alderman, K. (2007). Asynchronous Discussions and Assessment in Online Learning. Journal of Research on Technology in Education, 39(3), 309-328. https:// doi.org/10.1080/15391523.2007.10782485

Vranic, M., Pintar, D., \& Skocir, Z. (2007). The use of data mining in education environment. 9th International Conference on Telecommunications (pp. 243-250). Zagreb, Croatia. Retrieved from https://doi.org/10.1109/CONTEL.2007.381878 


\section{APPENDIX}

\section{A Appendix A}

Table A1 Core Behavioral Aspects (CBA)

\section{Category Course introduction}

CBA1 Teacher makes an introductory videoconference in the first two weeks of the course, and posts his/her CV and photo in the LMS

CBA2 Teacher, posts a course presentation in the LMS, outlining the course objectives and the subject importance

CBA3 Teacher schedules all course activities, topics, and sections/modules on the LMS calendar

CBA4 Teacher posts in the LMS both the teaching guide and the study guide for following the course

\section{Categories Evaluation system description}

CBA1 Teacher draws up an evaluation guide and posts it in the LMS from the beginning of the course

CBA2 Teacher identifies in detail which evaluation activities will take place online and which ones will be face-to-face

CBA3 Teacher uses a variety of evaluation tools within the LMS (peer assessment, rubrics, quizzes, assignments, etc.)

CBA4 Teacher posts an organized summary of all evaluation activities in the assessment tab within the LMS

\section{Category Time management}

CBA1 Teacher begins video lectures at the time indicated, or posts them on schedule

CBA2 Teacher maximizes video lecture time by minimizing potential interruptions from the students

CBA3 Teacher notifies in advance whenever there is a change in the date or time of video lectures

CBA4 Teacher makes the best use of time during online office hours

\section{Category General availability}

CBA1 Teacher defines days and times for online office hours to meet with students via videoconferencing

CBA2 Teacher schedules at least one session of online office hours per week

CBA3 Teacher responds to the student by email, chat, or even videoconference if the inquiry requires it

CBA4 Teacher responds to inquiries within 24-48 hours

\section{Category Organizational consistency}

CBA1 Teacher sticks with the days and times of online office hours throughout the course

CBA2 Teacher holds at least one video lecture per month, following what was indicated at the beginning of the course

CBA3 Teacher keeps all required resources for the course properly organized within the LMS (teaching material, evaluation activities, study guide, evaluation guide, etc.)

CBA4 Teacher follows the scheduled program of activities, topics, sections/modules throughout the course

\section{Category Evaluation system implementation}

CBA1 Teacher maintains grading method described in the course evaluation guide

CBA2 Teacher holds evaluation activities on the dates scheduled according to the official academic calendar

CBA3 Teacher carries out the same evaluation activities that were stated in the course evaluation guide

CBA4 Teacher offers students the chance to review evaluation activities online using LMS resources (email, chat, videoconference)

\section{Category Dealing with doubts}

CBA1 Teacher creates and maintains an atmosphere in the LMS forum that encourages students to express their doubts

CBA2 Teacher schedules individual or group videoconferences when questions cannot be resolved through email, chat, or the course forum

CBA3 Teacher responds to questions expressed in email, chat, or the course forum with specific messages containing clear, relevant information

CBA4 Teacher answers students' questions using examples from practical experiences

\section{Category Explicative capacity}

CBA1 Teacher uses video lectures every month to explain first-hand the most important concepts of the course

CBA2 Teacher, in addition to traditional presentations, also uses multimedia resources such as interactive presentations (Sway, Prezi, etc.) or podcasts

CBA3 Teacher summarizes critical content through concept maps

CBA4 Teacher combines theoretical with practical activities during the course

\section{Category Follow-up easiness}

CBA1 Teacher uses the LMS forum to give weekly/monthly reminders of aspects that are of interest to the course 
Table A1 continued

CBA2 Teacher assigns the student a manageable weekly workload

CBA3 Teacher encourages students to participate in the course through the course forum

CBA4 Teacher records the video lectures, so they can be watched or reviewed later

Category General satisfaction

CBA1 Teacher helps students develop the competencies established for the course

CBA2 Teacher uses a course design and structure within the LMS that helps students get the most out of the course

CBA3 Teacher demonstrates knowledge and appropriate skills to use LMS resources, applying them to make the course more attractive

CBA4 Teacher helps fulfill what was expected from this course 


\section{B Appendix B}

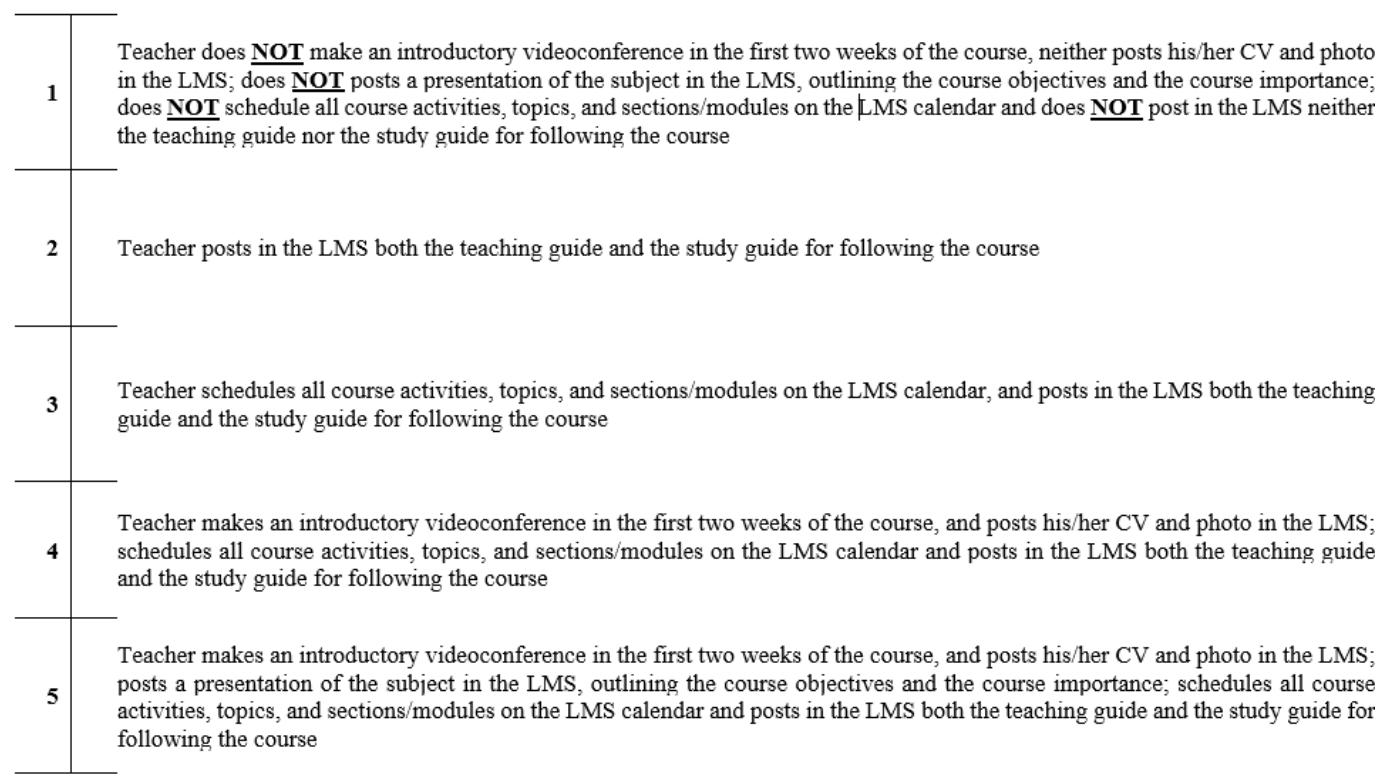

Figure B1 Course introduction

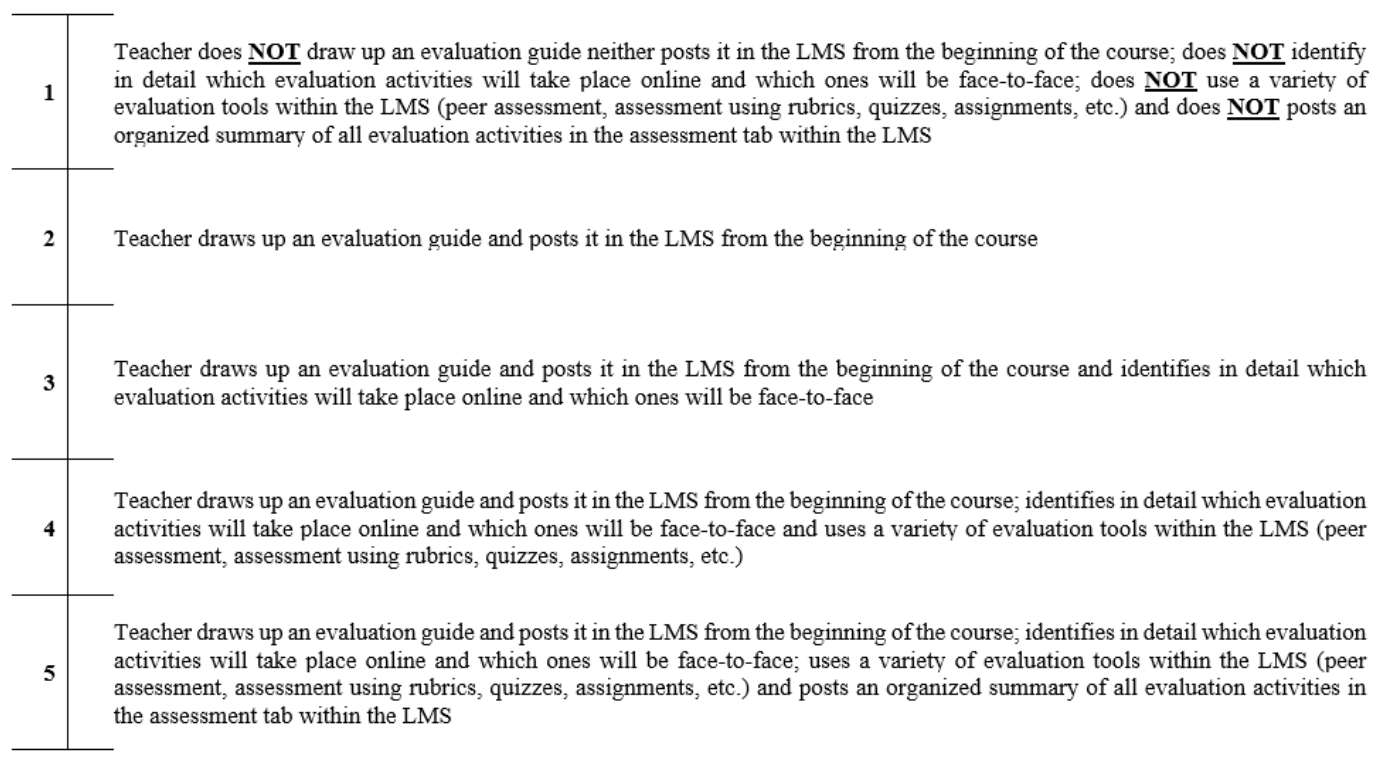

Figure B2 Evaluation system description 


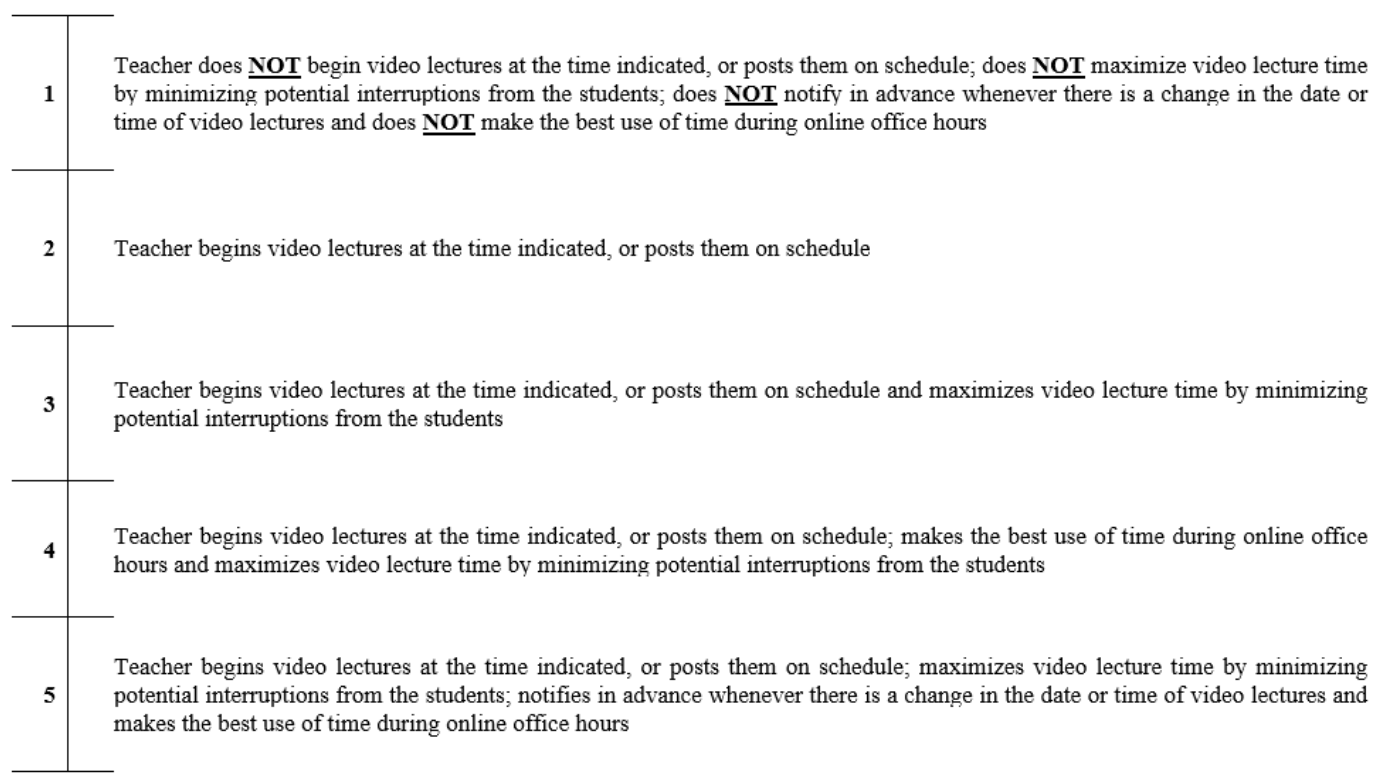

Figure B3 Time management

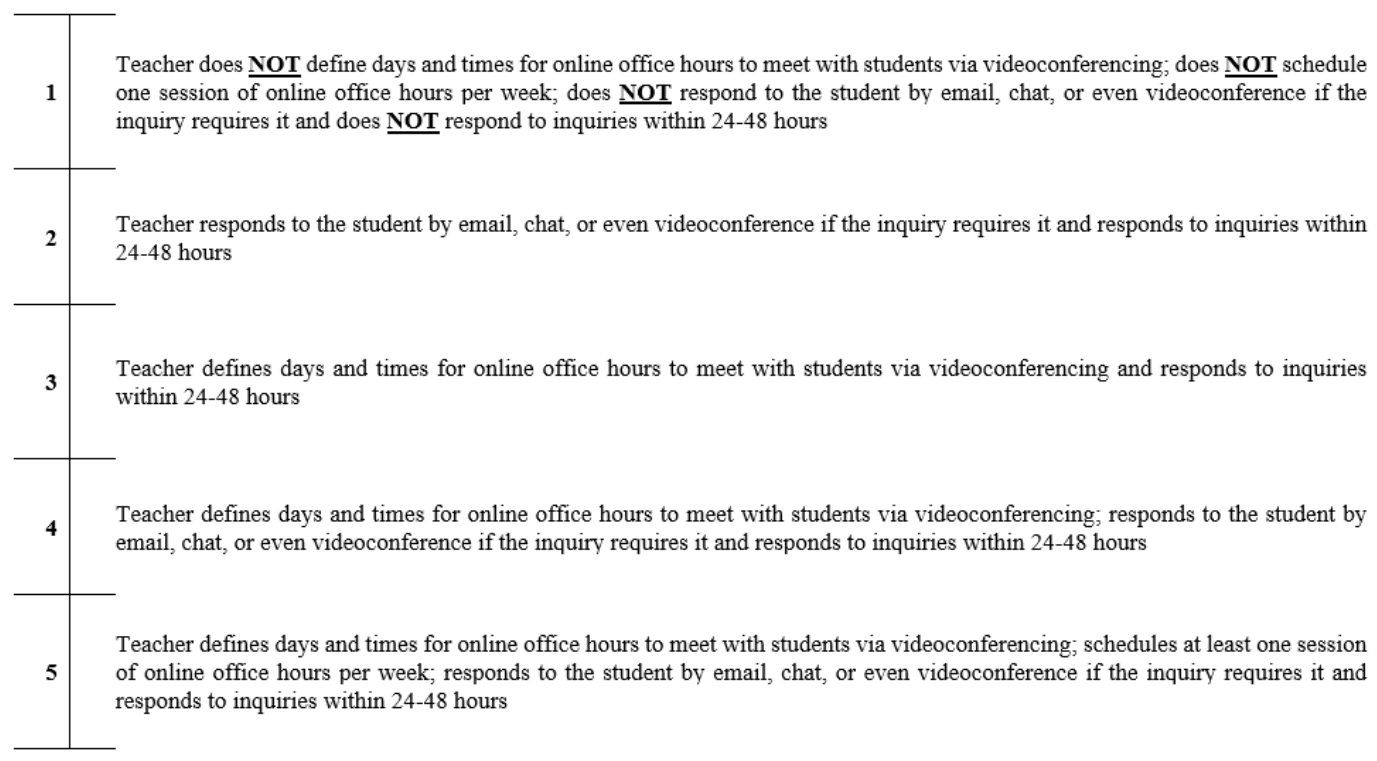

Figure B4 General availability 


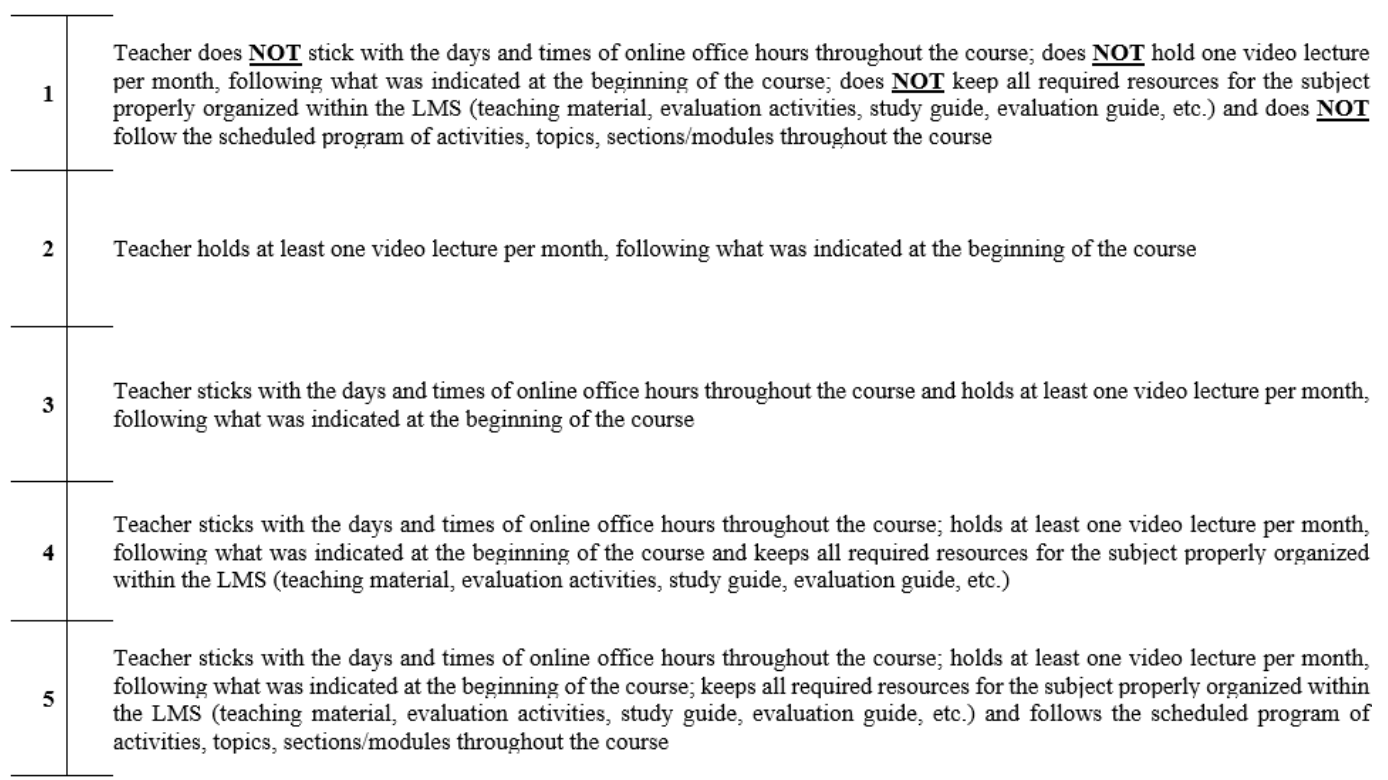

Figure B5 Organizational consistency

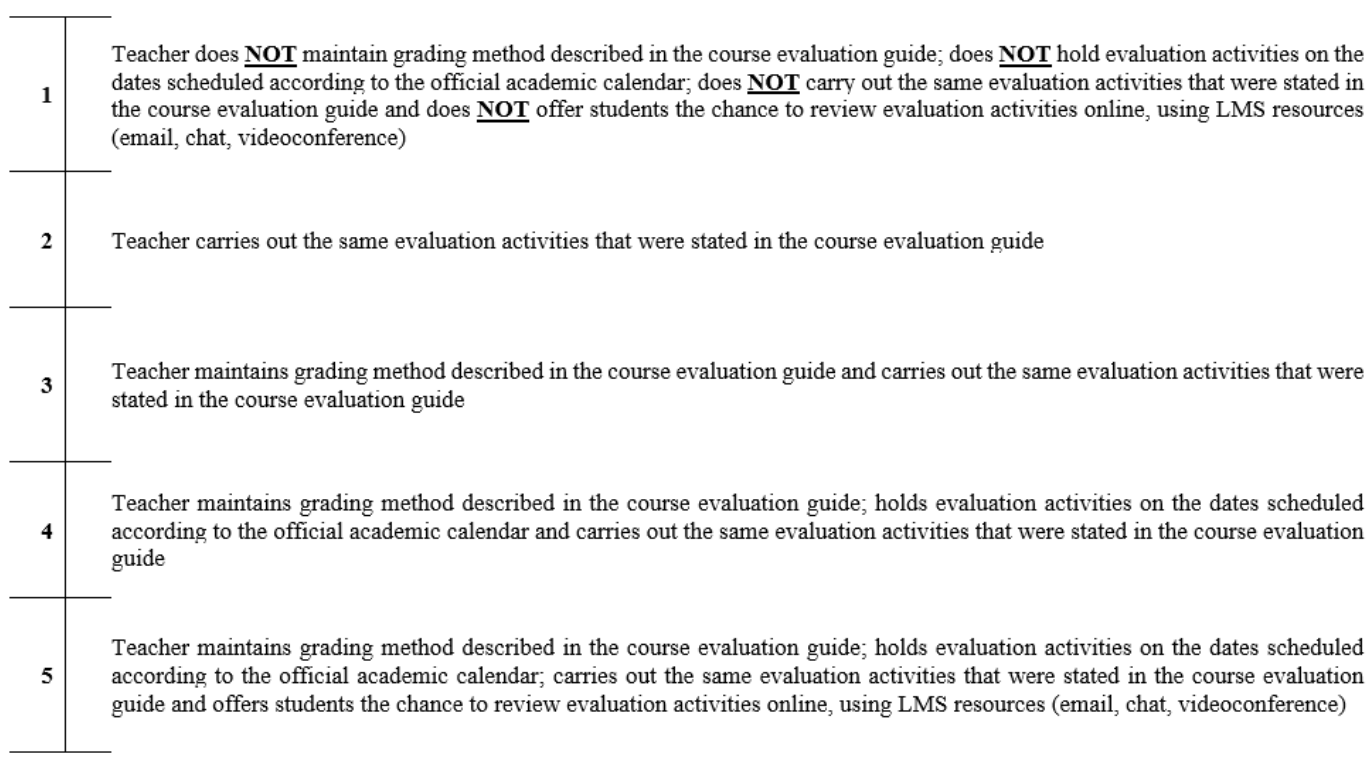

Figure B6 Evaluation system implementation 


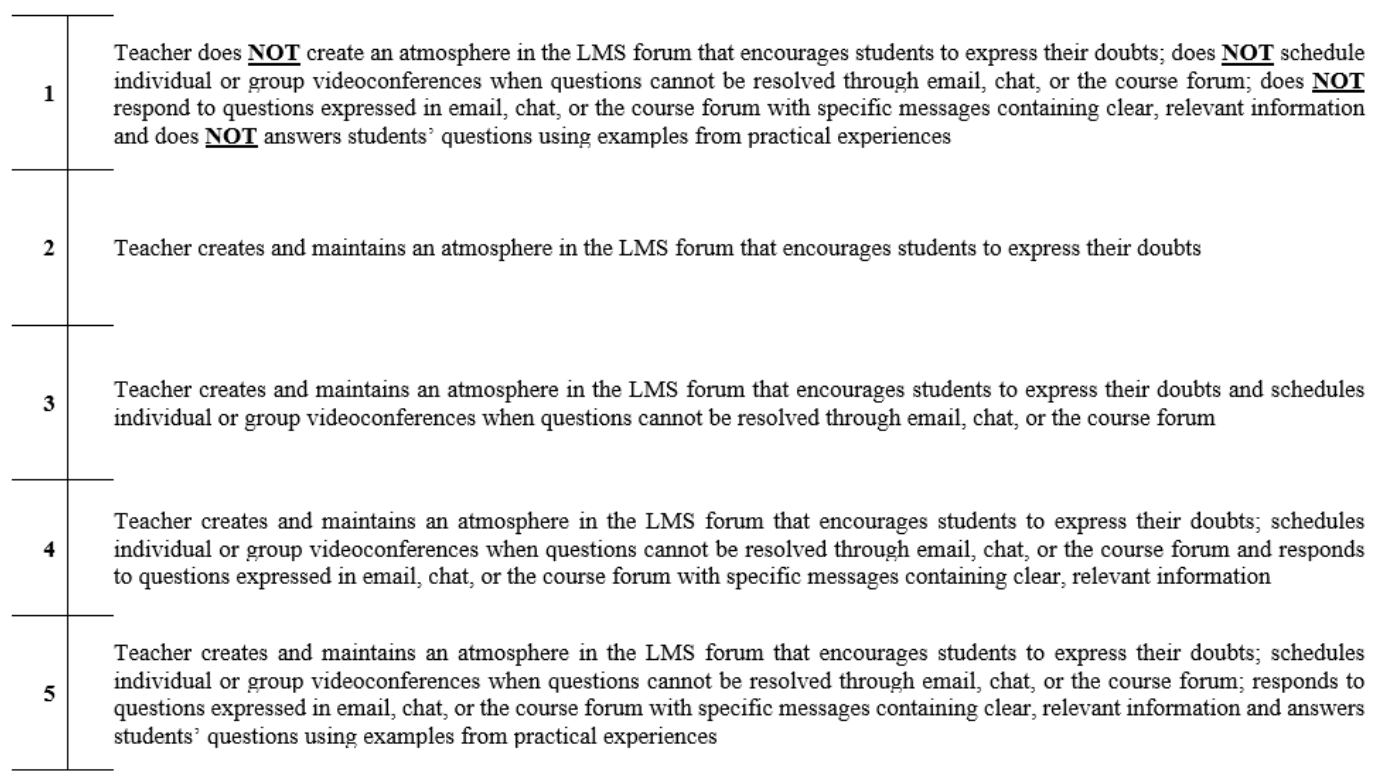

Figure B7 Dealing with doubts

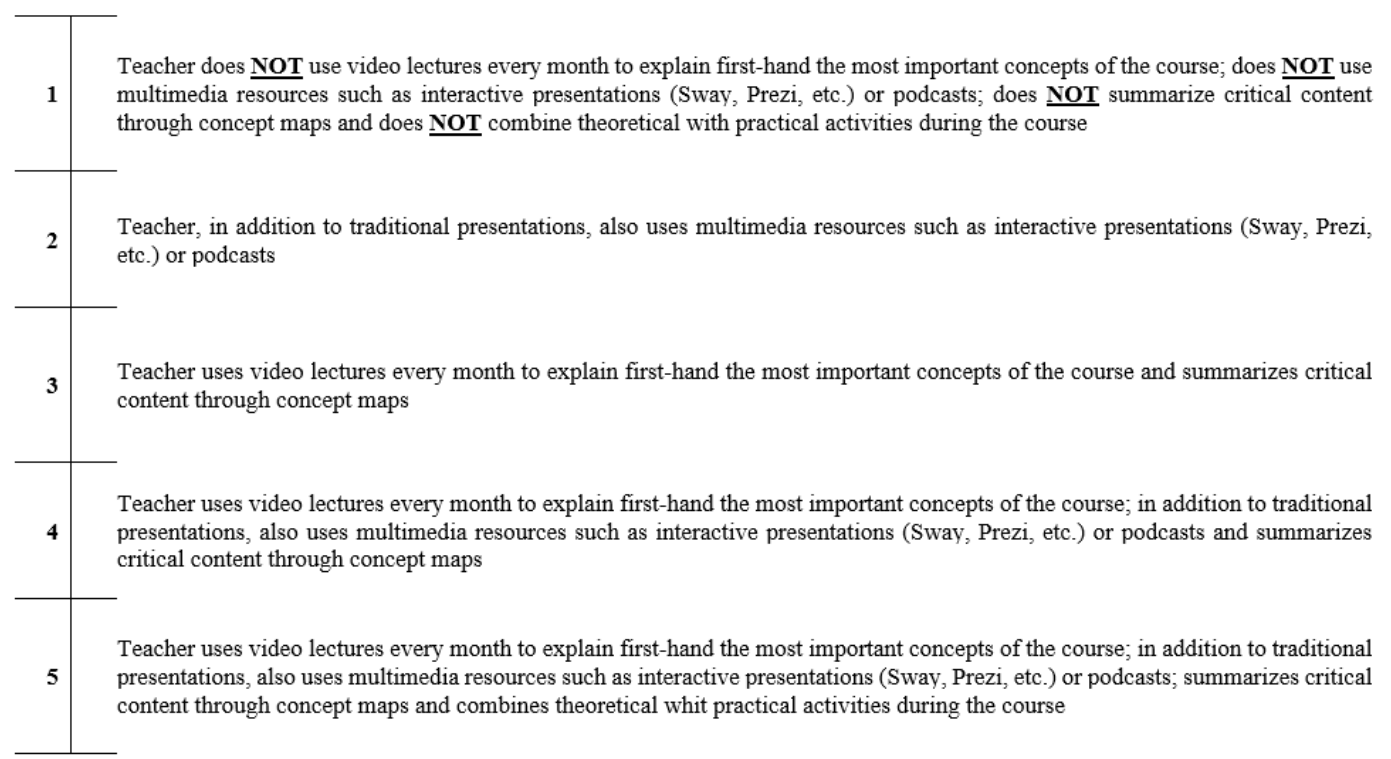

Figure B8 Explicative capacity 


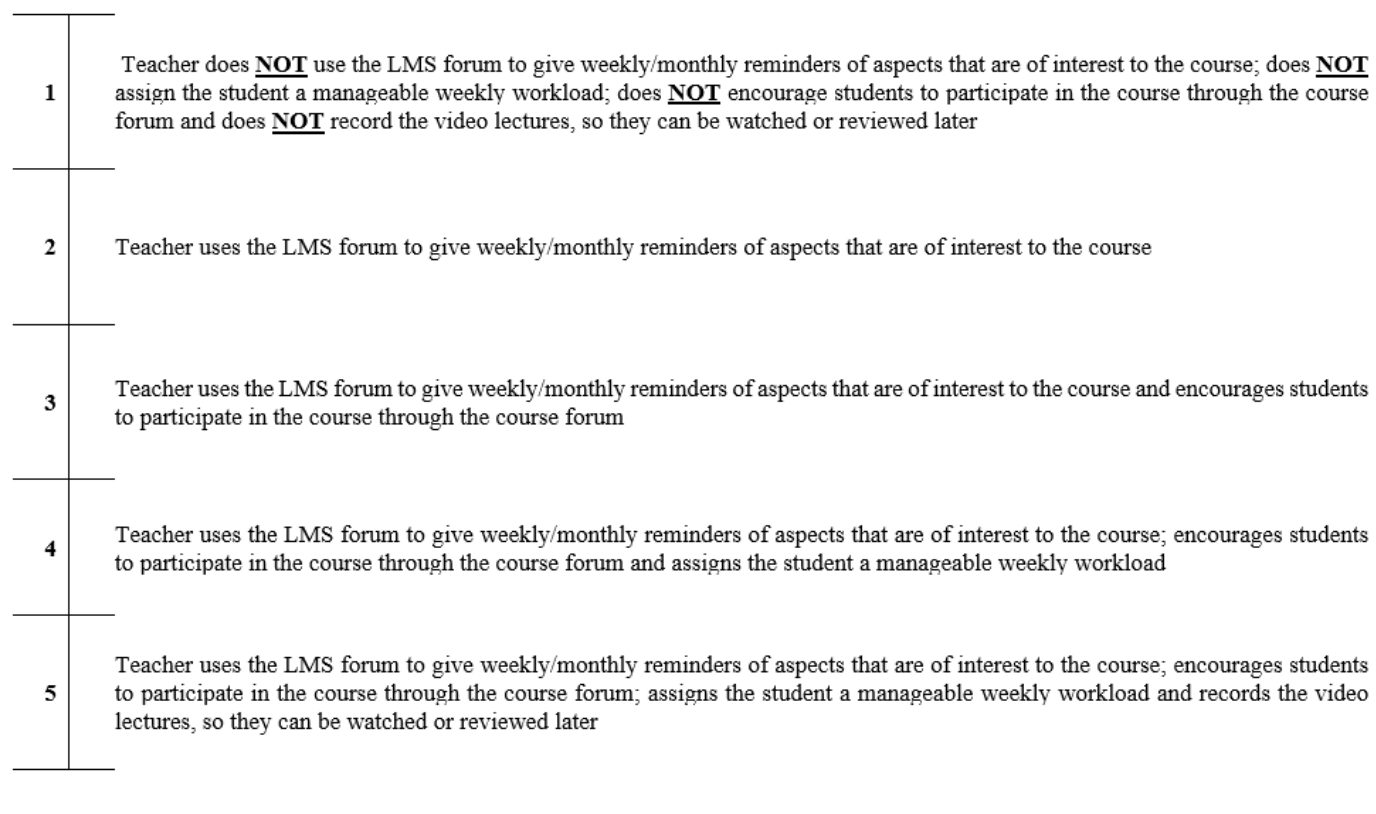

\section{Figure B9 Follow-upeasiness}

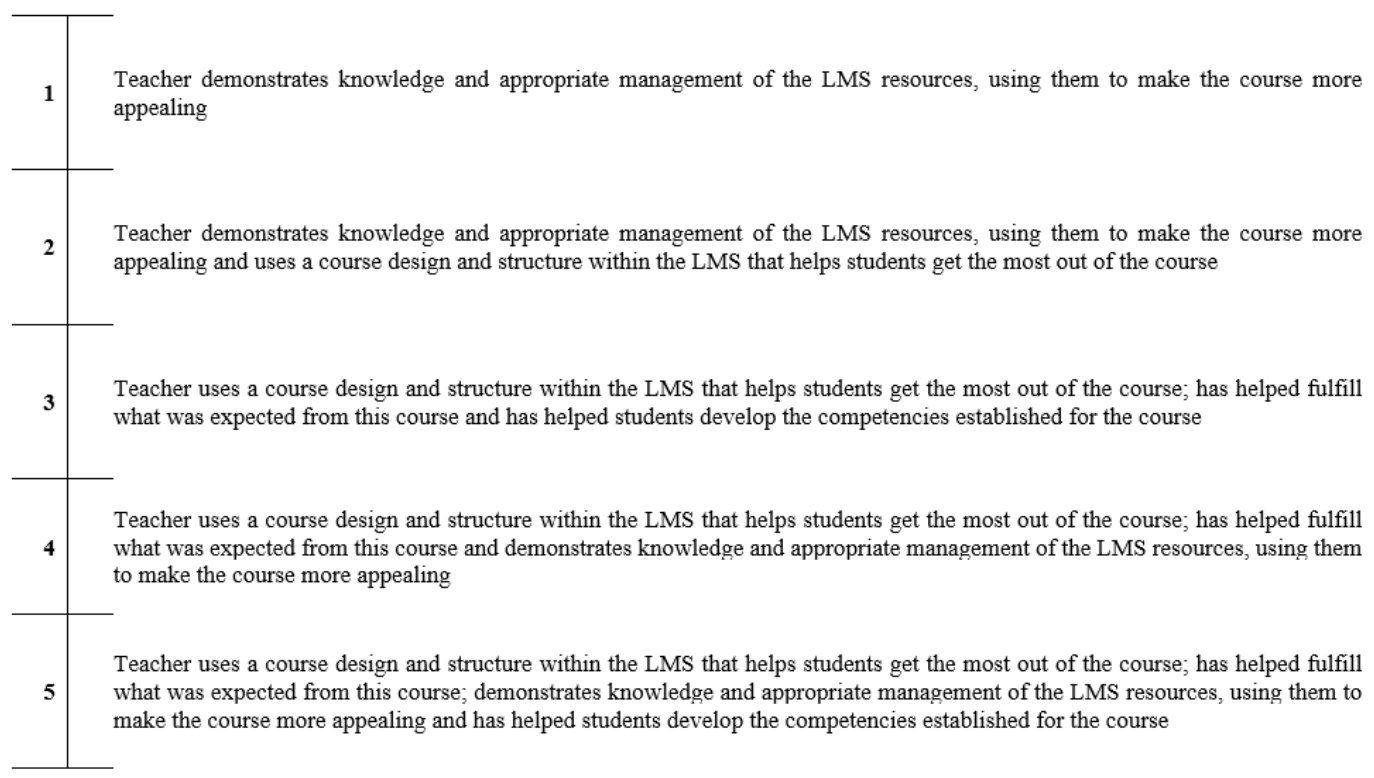

Figure B10 General satisfaction 